\title{
Analisis Faktor-Faktor yang Mempengaruhi Kesuksesan Penerapan Sistem Informasi Layanan Perkantoran (E-Layar): Studi Kasus Kementerian Kelautan dan Perikanan
}

\author{
Fadillah Ananda Arifah ${ }^{1 *}$, Diny Wahyuni ${ }^{2}$ \\ 1,2 Program Studi Sistem Informasi Bisnis, Fakultas Magister Manajemen Sistem \\ Informasi, Universitas Gunadarma, Depok, Jawa Barat, Indonesia.
}

\begin{abstract}
Abstrak. Dalam rangka mendukung penyelenggaran kepemerintahan yang baik (good governance) di lingkungan Kementerian Kelautan dan Perikanan serta meningkatnya keperluan administrasi terutama pada bidang persuratan dan disposisi perlu suatu upaya untuk menerapkan sistem yang terintegrasi dengan memanfaatkan teknologi informasi yang terhubung pada setiap unit organisasi atau unit kerja. Salah satu upaya yang dilakukan adalah membangun suatu aplikasi persuratan dan disposisi secara elektronik. Aplikasi persuratan dan disposisi secara elektronik atau E-Layar (Layanan Perkantoran Persuratan, Disposisi, dan Arsip) mulai di implementasikan pada tabun 2019 namun dalam penerapannya masib terdapat beberapa kekurangan. Berdasarkan uraian di atas, maka diperlukan analisis faktor-faktor yang mempengarubi kesuksesan penerapan e-layar. Penelitian ini menggunakan model kesuksesan Updated DeLone and McLean IS Success Model dengan 6 variabel penelitian, teknik analisis data menggunakan SEM dan olah data menggunakan perangkat lunak LISREL (Linear Structural Relationship). Berdasarkan hasil deskriptif persepsi responden, seluruh variabel laten memiliki tingkat kesukesesan yang baik. Berdasarkan hasil penelitian, selurub variabel manifes valid untuk mengukur konstruknya serta memiliki reliabilitas yang baik dan berdasarkan hasil uji hipotesis dengan error 0,1 (10\%), terdapat 4 bipotesis yang terbukti secara empiris dan 5 hipotesis yang tidak terbukti secara empiris.
\end{abstract}

Kata kunci: E-Layar; Updated DeLone; McLean IS Success Model; SEM.

\begin{abstract}
Implement an integrated system by utilizing information technology that is connected to each organizational unit or work unit was an effort to support the implementation of good governance in Ministry of Maritime Affairs and Fisheries as well as increasing administratives needs, especially in the correspondence and disposition sectors. One of the efforts is to build an application for correspondence and disposition electronically. Electronic correspondence and disposition applications or known as E-Layar (Office Services for Correspondence, Disposition, and Archives) began to be implemented in 2019 but there is some deficiency of the implementation. Based on the description, it is necessary to analyze the factors of the implementation E-Layar affect. This research uses the Updated DeLone and McLean IS Success Model success model with 6 research variables, SEM for the data analysis technique and LISREL software for the data processing. Based on the descriptive results of respondents's perceptions, all the latent variables have a good success rate. Based on the research results, all the manifest variables are valid to measure their constructs and have good reliability and based on the results of hypothesis testing with an error of 0.1 (10\%), there are 4 bypotheses that are empirically proven and 5 bypothesis that are not empirically proven.
\end{abstract}

Keywords: E-Layar; Updated DeLone; McLean IS Success Model; SEM.

*Author. Email: arifahananda@gmail.com ${ }^{1}$, dwahyuni@staff.gunadarma.ac.id ${ }^{2}$

DOI: https://doi.org/10.35870/emt.v6i1.493

Received: 31 October 2021, Revision: 14 November 2021, Accepted: 11 December 2021, Available Online: 1 January 2022.

Print ISSN: 2579-7972; Online ISSN: 2549-6204.

Copyright @ 2022. Published by Lembaga Otonom Lembaga Informasi dan Riset Indonesia (KITA INFO dan RISET). 


\section{Pendahuluan}

Instansi pemerintah merupakan unsur penyelenggara pemerintahan pusat dan pemerintahan daerah. Terdapat berbagai macam instansi pemerintah di Indonesia, salah satunya adalah Kementerian Kelautan dan Perikanan. Dalam rangka mendukung penyelenggaran kepemerintahan yang baik (good governance) di lingkungan Kementerian Kelautan dan Perikanan serta meningkatnya keperluan administrasi terutama pada bidang persuratan dan disposisi perlu suatu upaya untuk menerapkan sistem yang terintegrasi dengan memanfaatkan teknologi informasi yang terhubung pada setiap unit organisasi atau unit kerja. Salah satu upaya yang dilakukan adalah membangun suatu aplikasi persuratan dan disposisi secara elektronik.

Aplikasi persuratan dan disposisi merupakan salah satu sub sistem dari perkantoran elektronik di Kementerian Kelautan dan Perikanan yang dikembangkan dengan memanfaatkan teknologi berbasis jaringan komputer dan aplikasi web based yang dapat memproses data persuratan dan disposisi dalam program manajemen basis data (KAK, 2018).

Aplikasi persuratan dan disposisi atau lebih dikenal dengan nama E-Layar (Layanan Perkantoran Persuratan, Disposisi, dan Arsip) mulai di implementasikan pada tahun 2019. Pengenalan dan pelaksanaan e-layar dilakukan secara bertahap yakni melalui sosialiasi serta bimbingan teknis (bimtek) di seluruh Unit Kerja Eselon 1 dan Eselon 2 Pusat maupun UPT (Unit Pelaksana Teknik). Dalam penerapannya, masih terdapat beberapa kekurangan, diantaranya adalah 1) redudansi nomor surat, 2) penomoran surat secara otomatis belum diterapkan, 3) permasalahan terkait session, 4) bug, yang dapat menyebabkan aplikasi berjalan tidak normal atau tidak dapat digunakan sementara waktu.

Dari permasalahan diatas maka diperlukan suatu model kesuksesan yang digunakan untuk mengukur kesuksesan aplikasi e-layar serta teknik analisis yang digunakan untuk evaluasi hasil pengukuran dan strategi yang akan dikembangkan untuk aplikasi e-layar.
Faktor-faktor yang akan dianalisis pada penelitian ini di adaptasi dari Updated D $\mho M$ IS Success Model menggunakan 6 faktor atau variabel, di antaranya adalah kualitas sistem (system quality), kualitas informasi (information quality), kualitas layanan (service quality), penggunaan (use), kepuasan pengguna (user satisfaction), dan manfaat bersih (net benefit). Metode yang digunakan untuk mengukur variabel tersebut adalah metode SEM (Structural Equation Modeling) dan LISREL (Linear Structural Relationship) sebagai perangkat lunak untuk olah data.

\section{Tinjauan Literatur}

\section{Sistem Informasi}

Sistem informasi merupakan kumpulan komponen antara satu dengan komponen lainnya yang saling berhubungan yang bertujuan untuk menghasilkan suatu informasi (Farell, Saputra, \& Novid, 2018; Lestari \& Amri, 2020).

\section{Aplikasi E-Layar}

Aplikasi persuratan dan disposisi merupakan salah satu sub sistem dari perkantoran elektronik di Kementerian Kelautan dan Perikanan yang dikembangkan dengan memanfaatkan teknologi berbasis jaringan komputer dan aplikasi web based yang dapat memproses data persuratan dan disposisi dalam program manajemen basis data. Aplikasi e-layar terdiri dari 9 modul dan setiap modul memiliki fitur modul masing-masing (KAK, 2018)

\section{Updated DeLone and McLean Information System Success Model}

Sejak diperkenalkan pada tahun 1992, artikel DeLone and McLean Information System Success Model (1992) menjadi artikel yang paling banyak dikutip dalam literatur sistem informasi (Lowry et al., 2007). Pada tahun 1980, Peter Keen dalam Dwivedi et al (2012) menyatakan kurangnya dasar ilmiah dalam penelitian sistem informasi dan mengajukan pertanyaan mengenai variabel dependen apa yang seharusnya digunakan dalam penelitian sistem informasi. Banyak peneliti menjadi termotivasi oleh permintaan Delone dan McLean untuk pengembangan lebih lanjut dan validasi model mereka. Namun, sebagian besar peneliti membahas berbagai aspek kesuksesan sistem informasi sehingga membuat perbandingan menjadi sulit. Untuk mengatur 
sejumlah literatur yang ada serta untuk mengintegrasikan berbagai konsep dan temuan dan untuk menyajikan taksonomi yang komprehensif, DeLone dan McLean (1992) memperkenalkan model keberhasilan sistem informasi DeLone and McLean yang sudah dikembangkan. Model keberhasilan sistem informasi DeLone and McLean yang sudah dikembangkan memiliki 6 variabel, diantaranya kualitas sistem, kualitas informasi, kualitas layanan, penggunaan, kepuasan pengguna, dan manfaat bersih.

\section{SEM (Structured Equation Modeling)}

SEM adalah suatu teknik modeling statistik yang bersifat sangat cross-sectional, linear dan umum. Termasuk dalam SEM ini ialah analisis faktor (factor analysis), analisis jalur (path analysis) dan regresi (regression). Definisi lain menyebutkan structural equation modeling (SEM) adalah teknik analisis multivariat yang umum dan sangat bermanfaat yang meliputi versi-versi khusus dalam jumlah metode analisis lainnya sebagai kasus-kasus khusus (Sarwono, 2010).

\section{Metodologi Penelitian}

Objek pada penelitian ini adalah pengguna aplikasi e-Layar yaitu Pegawai Negeri Sipil (PNS) dan Sekretaris pada Sekretariat Jenderal, Kementerian Kelautan dan Perikanan. Jumlah sampel pada penelitian ini dengan batas toleransi kesalahan $0,1 \quad(10 \%)$ adalah 81 responden. Jenis data yang digunakan dalam penelitian ini adalah data primer berupa kuesioner yang berisi persepsi responden dengan skala Likert 1-5 (dari sangat tidak setuju sampai dengan sangat setuju). Sebelum kuesioner disebarkan kepada responden, peneliti melakukan uji pendahuluan kuesioner. Uji pendahuluan dilakukan terhadap 20 responden pengguna e-Layar pada unit kerja Pusat Data, Statistik, dan Informasi, Kementerian Kelautan dan Perikanan. Kuesioner yang telah diisi oleh responden akan dikelompokkan berdasarkan Jenis Kelamin, Pendidikan, Umur, dan Unit Kerja dan selanjutnya dianalisis menggunakan Structural Equation Modelling (SEM) dengan program Linier Structural Relation (LISREL).

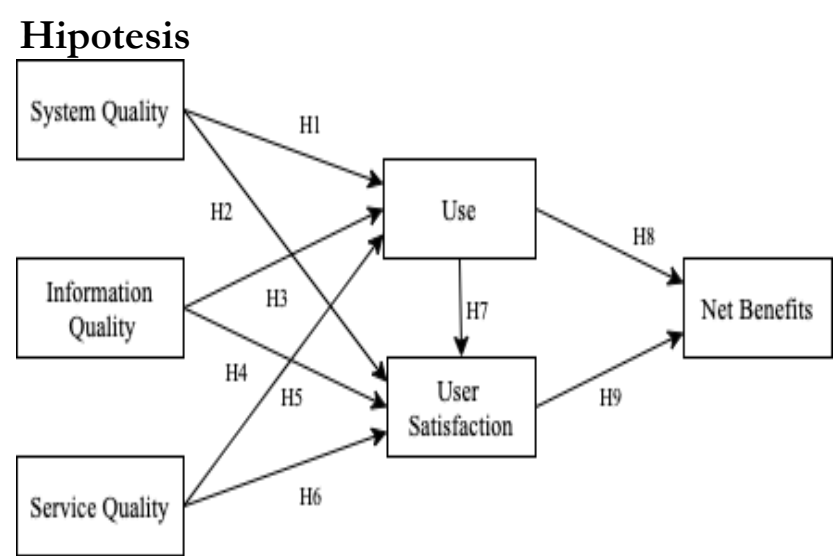

Gambar 1. Kerangka Hipotesis Yang Akan Diuji

Dalam DeLone and McLean Information System Success Model (1992), terdapat 6 variabel yang mempengaruhi kesuksesan suatu sistem informasi yang ditunjukkkan pada gambar 2.1, model tersebut menjelaskan bahwa kualitas sistem akan mempengaruhi penggunaan sistem dan kepuasan pengguna. Kualitas sistem yang lebih tinggi diharapkan menghasilkan kepuasan penggunaan dan pengguna yang lebih tinggi (DeLone and McLean, 2003:11). Penelitian yang dilakukan oleh $\mathrm{Hu}$ dan Wu (2016) menyatakan bahwa semakin tinggi kualitas informasi maka semakin tinggi probabilitas pengguna dalam menggunakan sistem. Dalam perspektif dimensi, hasil penelitian $\mathrm{Hu}$ dan $\mathrm{Wu}$ menunjukkan ada 3 dimensi dalam model akhir, salah satunya adalah akurasi (kualitas informasi).

Berdasarkan studi empiris yang dilakukan oleh Jiang et al (2002), untuk mengukur kesuksesan sistem informasi, kualitas layanan dapat menjadi variabel yang paling penting. Menurut Hudin dan Riana (2016), hasil penelitian menunjukkan terdapat 2 variabel yang berpengaruh besar terhadap keberhasilan sistem, salah satunya adalah kepuasan pengguna. Hal tersebut sejalan dengan penelitian yang dilakukan oleh Livari (2005) yang menyatakan bahwa kepuasan pengguna cukup berpengaruh untuk dampak individu dan berdampak pada penggunaan sistem.

Berdasarkan penelitian yang telah dilakukan oleh Utami dan Samopa (2013), menyatakan bahwa penggunaan dan kepuasan pengguna sistem yang diuji kesuksesannya memiliki pengaruh positif yang signifikan terhadap manfaat-manfaat bersih sistem. Berdasarkan 
bukti empiris yang telah diuraikan diatas, berikut 9 hipotesis yang akan diuji, yaitu sebagai berikut :

Tabel 1. Hipotesis Penelitian

\begin{tabular}{lll}
\hline \multicolumn{3}{c}{ Hipotesis } \\
\hline H1 & $\begin{array}{l}\text { Kualitas Sistem Berpengaruh Positif } \\
\text { Terhadap Penggunaan E-Layar }\end{array}$ \\
H2 & $\begin{array}{l}\text { Kualitas Sistem Berpengaruh Positif } \\
\text { Terhadap Kepuasan Pengguna E-Layaar } \\
\text { Kualitas Informasi Berpengaruh Positif }\end{array}$ \\
H3 & $\begin{array}{l}\text { Terhadap Penggunaan E-Layar } \\
\text { Kualitas Informasi Berpengaruh Positif } \\
\text { Terhadap Kepuasan Pengguna E-Layar }\end{array}$ \\
H5 & $\begin{array}{l}\text { Kualitas Layanan Berpengaruh Positif } \\
\text { Terhadap Pengunaan E-Layar }\end{array}$ \\
H6 & $\begin{array}{l}\text { Kualitas Layanan Berpengaruh Positif } \\
\text { Terhadap Kepuasan Pengguna E-Layar }\end{array}$ \\
H7 & $\begin{array}{l}\text { Penggunaan Berpengaruh Positif } \\
\text { Terhadap Kepuasan Pengguna E-Layar } \\
\text { H8 Penggunaan Berpengaruh Positif } \\
\text { Terhadap Manfaat Bersih E-Layar }\end{array}$ \\
H9 & $\begin{array}{l}\text { Kepuasan Pengguna Berpengaruh Positif } \\
\text { Terhadap Manfaat Bersih E-Layar }\end{array}$ \\
\hline
\end{tabular}

\section{Variabel Penelitian}

Variabel penelitian ini diklasifikasikan ke dalam beberapa variabel (Wijanto, 2008) diantaranya :

1. Variabel Laten

Variabel laten adalah variabel yang tidak dapat diukur secara langsung. Terdapat 6 variabel laten pada penelitian ini diantaranya adalah kualitas sistem, kualitas informasi, kualitas layanan, penggunaan, kepuasan pengguna, dan manfaat bersih.

2. Variabel Manifes

Variabel yang digunakan untuk menjelaskan atau mengukur sebuah variabel laten (Santoso, 2011:7). Variabel manifes pada penelitian ini adalah indikator yang terdapat pada setiap variabel laten.

3. Variabel Eksogen

Variabel eksogen merupakan variabel yang tidak dipengaruhi variabel lain dan mempengaruhi variabel dependen. Variabel eksogen pada penelitian ini adalah kualitas sistem, kualitas informasi, dan kualitas layanan.

4. Variabel Endogen

Variabel atau sering juga dikenal dengan variabel dependen merupakan variabel yang dipengaruhi oleh var exogenous. Variabel endogen pada penelitian ini adalah penggunaan, kepuasan pengguna, dan manfaat bersih.

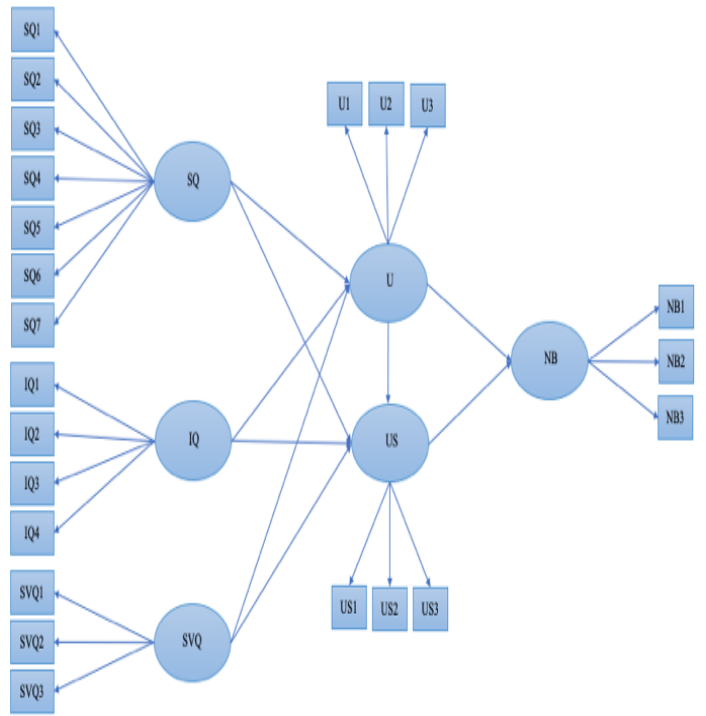

Gambar 2. Model Penelitian

Keterangan:

SQ : System Quality

IQ : Information Quality

SVQ : Service Quality

$\mathrm{U} \quad$ : Use

US : User Satisfaction

NB : Net Benefit

\section{Teknik Analisis Data}

Teknik analisis yang digunakan adalah teknik SEM (Structured Equation Modeling) dengan menggunakan perangkat lunak LISREL (Linier Structural Relationship) sebagai tools olah data. Menurut Bollen dan Long (1993), terdapat 5 tahap dalam prosedur SEM, diantaranya :

1. Spesifikasi Model (Model Specification) Berikut path diagram yang menggambarkan model penelitian ini:

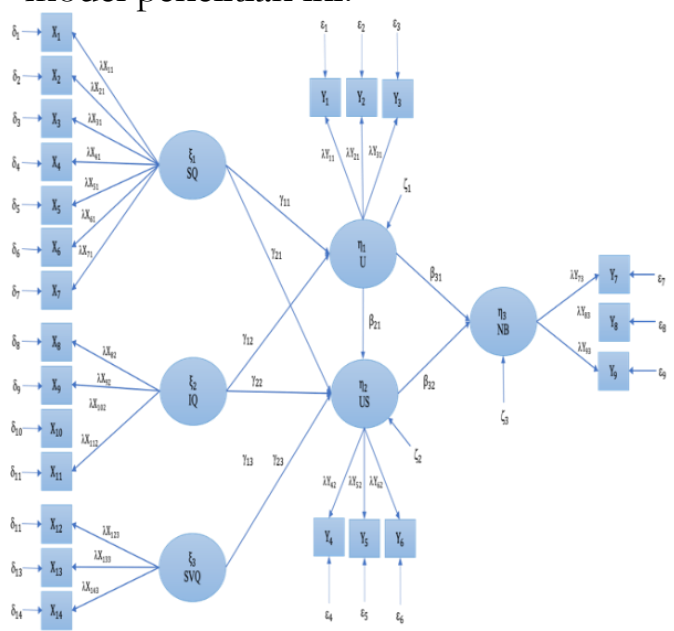

Gambar 3. Path Diagram 
2. Identifikasi (Identification)

3. Estimasi (Estimation)

4. Uji Kecocokan (Testing Fit)

5. Respesifikasi (Respesification).

\section{Hasil dan Pembahasan}

\section{Karakteristik Responden}

Profil responden pengguna aplikasi e-layar yang meliputi jenis kelamin, usia, pendidikan terakhir, unit kerja, lama pengalaman bekerja, role aplikasi e-layar dan pengalaman menggunakan aplikasi e-layar.

\section{Statistik Deskriptif}

Dalam penelitian ini, penilaian diukur dengan skor 1 untuk jawaban sangat tidak setuju, 2 untuk jawaban tidak setuju, 3 untuk jawaban netral, 4 untuk jawaban setuju, dan 5 untuk jawaban sangat setuju. Skor persepsi terendah adalah 1. Skor persepsi tertinggi adalah 5 . Sehingga diperoleh batasan interval yaitu 0,8 .

\begin{tabular}{ll}
\multicolumn{2}{c}{ Tabel 2. Kriteria Persepsi } \\
\hline \multicolumn{1}{c}{ Interval } & \multicolumn{1}{c}{ Keterangan } \\
\hline $1,00-1,80$ & Sangat Tidak \\
& Baik \\
$1,81-2,60$ & Tidak Baik \\
$2,61-3,40$ & Netral \\
$3,41-4,20$ & Baik \\
$4,21-5,00$ & Sangat Baik \\
\hline
\end{tabular}

Berdasarkan hasil deskriptif persepsi responden, dapat disimpulkan seluruh variabel memiliki nilai interval diantara 3,41-4,20 yang artinya memiliki tingkat kesuksesan yang baik.

\section{Hasil Analisis}

\section{Validitas Konstruk}

Menurut Igbaria et al (1997) yang menggunakan guidelines dari Hair et al (1995) dalam Wijanto (2008:65) tentang relative importance and significant of the factor loading of each item, menyatakan bahwa standardized loading $\geq 0.50$ adalah very significant.
Tabel 3. Hasil Validitas Konstruk

\begin{tabular}{llccc}
\hline Variabel & Indikator & $\begin{array}{c}\text { Loading } \\
\text { Factors }\end{array}$ & $\begin{array}{c}\text { Standardized } \\
\text { Loading }\end{array}$ & Keterangan \\
\hline System & SQ1 & 0,73 & $\geq 0.50$ & Valid \\
Quality & SQ3 & 0,81 & $\geq 0.50$ & Valid \\
(SQ) & 0,57 & $\geq 0.50$ & Valid \\
& SQ4 & 0,74 & $\geq 0.50$ & Valid \\
& SQ5 & 0,72 & $\geq 0.50$ & Valid \\
& SQ6 & 0,81 & $\geq 0.50$ & Valid \\
& SQ7 & 0,8 & $\geq 0.50$ & Valid \\
\hline Informati & IQ1 & 0,8 & $\geq 0.50$ & Valid \\
on & IQ2 & 0,73 & $\geq 0.50$ & Valid \\
Quality & IQ3 & 0,61 & $\geq 0.50$ & Valid \\
(IQ) & IQ4 & 0,8 & $\geq 0.50$ & Valid \\
\hline Service & SVQ1 & 0,77 & $\geq 0.50$ & Valid \\
Quality & SVQ2 & 0,64 & $\geq 0.50$ & Valid \\
(SVQ) & SVQ3 & 0,79 & $\geq 0.50$ & Valid \\
\hline Use & U1 & 0,8 & $\geq 0.50$ & Valid \\
(U) & U2 & 0,74 & $\geq 0.50$ & Valid \\
\hline User & U3 & 0,71 & $\geq 0.50$ & Valid \\
Satisfactio & US2 & 0,78 & $\geq 0.50$ & Valid \\
$n$ & US3 & 0,79 & $\geq 0.50$ & Valid \\
(US) & & 0,79 & $\geq 0.50$ & Valid \\
\hline Net & NB1 & 0,79 & $\geq 0.50$ & Valid \\
Benefit & NB2 & 0,66 & $\geq 0.50$ & Valid \\
(NB) & NB3 & 0,73 & $\geq 0.50$ & Valid \\
\hline & & & &
\end{tabular}

\section{Reliabilitas Konstruk}

Hair et al (1998) dalam Wijanto (2008:66) menyatakan bahwa sebuah konstruk mempunyai realibilitas yang baik jika:

a. Nilai Construct Reliability (CR)-nya $\geq 0.70$

b. Nilai Variance Extracted (VE)-nya $\geq 0.50$

Tabel 4. Hasil Reliabilitas Konstruk

\begin{tabular}{lrrr}
\hline Variabel & $\begin{array}{c}\text { Construct } \\
\text { Reliability }\end{array}$ & $\begin{array}{l}\text { Average } \\
\text { Variance } \\
\text { Extracted }\end{array}$ & Keterangan \\
\hline System Quality (SQ) & 0,896 & 0,554 & Reliabel \\
Information Quality & 0,826 & 0,546 & Reliabel \\
(IQ) & & & \\
Service Quality (SVQ) & 0,779 & 0,542 & Reliabel \\
Use (U) & 0,795 & 0,564 & Reliabel \\
User Satisfaction (US) & 0,830 & 0,619 & Reliabel \\
Net Benefit (NB) & 0,772 & 0,531 & Reliabel \\
\hline
\end{tabular}




\section{Evaluasi Pengukuran Model}

Pada penelitian ini pengukuran model dilakukan pada tahap uji kecocokan (testing fit) melalui beberapa tahapan, yaitu kecocokan keseluruhan model yang terdiri dari ukuran kecocokan absolut, ukuran kecocokan inkremental, dan ukuran kecocokan persimoni. Berdasarkan hasil penelitian, terdapat 7 ukuran GOF yang menunjukkan kecocokan yang kurang baik (poor fit), 1 ukuran GOF yang menunjukkan marginal fit dan 8 ukuran GOF yang menunjukkan kecocokan yang baik (good fit). Sehingga dapat disimpulkan bahwa uji kecocokan keseluruhan model (overall model fit) adalah baik.

\section{Uji Hipotesis}

Dari 9 hipotesis yang diuji, terdapat 5 hipotesis yang tidak terbukti signifikan dan 4 hipotesis yang terbukti signifikan.

\section{Kesimpulan dan Saran}

\section{Kesimpulan}

Berdasarkan hasil penelitian yang telah diuraikan pada bab sebelumnya, dapat disimpulkan bahwa model DeLone and McLean terbukti signifikan secara empiris dalam melihat faktor-faktor yang mempengaruhi kesuksesan penerapan aplikasi e-layar. Berikut ini hasil pengujian masingmasing hipotesa, yaitu sebagai berikut :

1. Kualitas Sistem (System Quality) berpengaruh positif terhadap Penggunaan (Use)

2. Kualitas Sistem (System Quality) berpengaruh positif terhadap Kepuasan Pengguna (User Satisfaction)

3. Kualitas Informasi (Information Quality) tidak berpengaruh positif terhadap Penggunaan (Use)

4. Kualitas Informasi (Information Quality) tidak berpengaruh positif terhadap Kepuasan Pengguna (User Satisfaction)

5. Kualitas Layanan (Service Quality) tidak berpengaruh positif terhadap Penggunaan (Use)

6. Kualitas Layanan (Service Quality) berpengaruh positif terhadap Kepuasan Pengguna (User Satisfaction)
7. Penggunaan (Use) tidak berpengaruh positif terhadap Kepuasan Pengguna (User Satisfaction)

8. Penggunaan (Use) tidak berpengaruh positif terhadap Manfaat Bersih (Net Benefit)

9. Kepuasan Pengguna (User Satisfaction) berpengaruh positif terhadap Manfaat Bersih (Net Benefit)

\section{Saran}

Berdasarkan penelitian yang telah dilakukan, terdapat beberapa saran yaitu sebagai berikut :

1. Kualitas informasi pada aplikasi e-layar perlu ditingkatkan kualitasnya terutama pada indikator completeness. Indikator tersebut memperoleh rata-rata terkecil sehingga perlu ditingkatkan kembali agar informasi surat masuk, surat keluar, dan disposisi yang disajikan dapat dipahami oleh pengguna secara jelas dan lengkap.

2. Kualitas layanan merupakan variabel dengan rata-rata terkecil sehingga perlu ditingkatkan kualitasnya secara keseluruhan. Salah satunya adalah dengan membentuk tim belpdesk.

3. Untuk unit pengembang, perlu diadakannya sosialisasi tentang penggunaan aplikasi e-layar baik di Pusat maupun UPT (Unit Pelaksana Teknis) agar pengguna lebih memahami fitur-fitur dan alur proses pada aplikasi e-layar.

4. Untuk peneliti selanjutnya, dapat menggunakan sampel dengan batasan yang lebih luas (seluruh eselon I di Kementerian Kelautan dan Perikanan Pusat) serta dapat menambahkan indikator dan variabel lain untuk diuji.

\section{Daftar Pustaka}

Bollen, K. \& Long, S. J., 1993. Testing Structural Equation Models. Thousand Oaks(California): SAGE Publication.

Delone, W. \& Mclean, E., 1992. Information Systems Success: The Quest for The Dependent Variable. Information Systems Research, 3(1), pp. 60-95. 
Delone, W. \& Mclean, E., 2003. The DeLone and McLean Model of Information Systems Success: A Ten-Year Update. Journal of Management Information Systems, April.

Dwivedi, Y. K., Wade, M. R. \& Schneberger, S. L., 2012. Information Systems Theory Explaining and Predicting Our Digital Society. New York: Springer.

Farell, G., Saputra, H. K., \& Novid, I. (2018). Rancang bangun sistem informasi pengarsipan surat menyurat (studi kasus fakultas teknik unp). Jurnal Teknologi Informasi dan Pendidikan, 11(2), 55-62.

Hasibuan, Z. A., 2007. Metodologi Penelitian Pada Bidang Ilmu Komputer dan Teknologi Informasi. Jakarta Pusat(Jakarta): s.n.

Hu, X. \& Wu, K., 2016. Assessing Information Technology Systems in The Environmental Arena of China: A Validation of The DeLone and McLean Information Systems Success Model. Juni.

Hudin, J. M. \& Riana, D., 2016. Kajian Keberhasilan Penggunaan Sistem Informasi Accurate dengan Menggunakan Model Kesuksesan Sistem Informasi DeLone dan McLean. Jurnal Sistem Informasi Journal of Information Systems), pp. 1-8.

Jiang, J. \& Klein, G., 2002. Measuring Information Systems Service Quality: SERVQUAL from The Other Side. IEEE Transactions on Systems, Man, and Cybernetics, 26(2), pp. 145-166.

Kerangka Acuan Kerja (KAK) tahun 2018 tentang Aplikasi Persuratan dan Disposisi. Jakarta: Kementerian Kelautan dan Perikanan.
Lestari, K. C., \& Amri, A. M. (2020). Sistem Informasi Akuntansi Beserta Contoh Penerapan Aplikasi Sia Sederhana Dalam UMKM). Deepublish.

Livari, J., 2005. An Empirical Test Of The DeLone and McLean Model Of Information System. Volume 36.

Lowry, G. R. \& Turner, R. L., 2007. Information Systems and Technology Education: From the University to the Workplace. s.l.:s.n.

Peraturan Menteri Kelautan dan Perikanan Republik Indonesia tahun 2018-2022 tentang Master Plan Teknologi Informasi Kementerian Kelautan dan Perikanan. Jakarta: Kementerian Kelautan dan Perikanan.

Santoso, S., 2011. Structural Equation Modeling. Jakarta(Jakarta): PT Elex Media Komputindo.

Sarwono, J., 2010. Pengertian Dasar Structural Equation Modeling (SEM). Januari.

Utami, A. W. \& Samopa, F., 2013. Analisa Kesuksesan Sistem Informasi Akademik di Perguruan Tinggi dengan Menggunakan D \& M IS Success Model (Studi Kasus: ITS Surabaya). Jurnal SISFO : Inspirasi Profesional Sistem Informasi, 1 September.4(5).

Wijanto, S. H., 2008. Structural Equation Modeling dengan Lisrel 8.8. Yogyakarta(Yogyakarta): Graha Ilmu. 